\title{
Noninvasive assessment of clinical and pathological characteristics of patients with IgA nephropathy by diffusion kurtosis imaging
}

\author{
Ping Liang, Shichao Li, Guanjie Yuan, Kangwen He, Anqin Li, Daoyu Hu, Zhen Li and Chuou Xu* (1)
}

\begin{abstract}
Objectives: To explore the diagnostic performance of diffusion kurtosis imaging (DKI) in evaluating the clinical and pathological characteristics of patients with immunoglobulin A nephropathy (IgAN) compared with conventional DWI.
\end{abstract}

Materials and methods: A total of $28 \mathrm{IgAN}$ patients and 14 healthy volunteers prospectively underwent MRI examinations including coronal T2WI, axial T1WI, T2WI, and DWI sequences from September 2020 to August 2021. We measured mean kurtosis (MK), mean diffusivity (MD), and apparent diffusion coefficient (ADC) by using MR Body Diffusion Toolbox v1.4.0 (Siemens Healthcare). Patients were divided into three groups according to their estimated glomerular filtration rate (eGFR) (Group1, healthy volunteers without kidney disease or other diseases that affect renal function; Group2, IgAN patients with eGFR $>60 \mathrm{~mL} / \mathrm{min} / 1.73 \mathrm{~m}^{2}$; Group3, IgAN patients with eGFR $<60 \mathrm{~mL} / \mathrm{min} / 1.73 \mathrm{~m}^{2}$ ). Oneway analysis of variance, Pearson or Spearman correlation, and receiver operating characteristic curves were applied in our statistical analysis.

Results: $\mathrm{MK}_{\text {Cortex }}$ and $A \mathrm{AC}_{\text {Cortex }}$ showed significant differences between the Group1 and Group2. $\mathrm{MK}_{\text {Cortex' }} \mathrm{MD}_{\text {Cortex }}$ $A D C_{\text {Cortex }}$ MK $M_{\text {Medullar }}$ and $A D C_{\text {Medulla }}$ showed significant differences between Group2 and Group3. MK highest correlation with CKD stages $(r=0.749, p<0.001)$, and tubulointerstitial lesion score $(r=0.656, p<0.001)$. $\mathrm{MD}_{\text {cortex }}$ had the highest correlation with glomerular lesion score $(r=-0.475, p=0.011)$. MK $\mathrm{Cortex}_{\text {had }}$ he highest AUC (AUC $=0.923$ ) for differentiating Group1 from Group2, and $M_{\text {Cortex }}$ had the highest AUC $(A \cup C=0.924)$ for differentiating Group2 from Group3, followed by MK Medulla $(A \cup C=0.923$ ).

Conclusions: DKI is a feasible and reliable technique that can assess the clinical and pathological characteristics of IgAN patients and can provide more valuable information than conventional DWI, especially $\mathrm{MK}_{\text {Cortex }}$

Keywords: Diffusional kurtosis imaging, Immunoglobulin A nephropathy, Mean kurtosis, Mean diffusivity, Apparent diffusion coefficient

*Correspondence: xchuou@163.com

Department of Radiology, Tongji Hospital, Tongji Medical College,

Huazhong University of Science and Technology, 1095 Jiefang Avenue, Wuhan 430030, Hubei, China

\section{Key points}

- DKI may be a feasible technique to evaluate the clinical and pathological characteristics of patients with IgAN.

- MK of the renal cortex derived from DKI may provide more valuable information than ADC. 
- MK of the renal cortex may be an excellent parameter for the evaluation of early kidney changes in patients with IgAN.

\section{Introduction}

Immunoglobulin A nephropathy (IgAN) is the most common glomerular disease in the world, which is characterized by the presence of $\operatorname{IgA}$ dominant or codominant immune deposits in the glomeruli [1]. The incidence of IgA nephropathy is 2.5 cases per 100,000 adults per year, and its prevalence is always underestimated because not all patients with suspected renal insufficiency will undergo a kidney biopsy [2]. IgAN is a chronic and progressive disease with various clinical manifestations (from asymptomatic to gross hematuria) and nearly $14-39 \%$ patients will develop end stage renal disease (ESRD) within 20 years after diagnosis [3]. Histopathological findings, including glomerular sclerosis, renal tubular atrophy and interstitial fibrosis, are the main independent risk factors for predicting the progression of IgAN and are essential for clinical treatment and prognostic evaluation [4]. However, kidney biopsy is an invasive and traumatic procedure, which may cause complications such as bleeding and infection. Moreover, it is difficult to repeat biopsy for longitudinal monitoring due to sampling errors [5]. Therefore, it is necessary to find a noninvasive method with high reproducibility and easy implementation in clinical practice to evaluate the pathological and clinical characteristics of IgAN.

A Working Group of the International IgA Nephropathy Network and the Renal Pathology Society reported that initial estimated glomerular filtration rate (eGFR) based on creatinine and urinary protein excretion at the time of renal biopsy are the clinical parameters which are the risk factors of IgAN and are associated with renal prognosis [6]. However, the sensitivity and specificity of the eGFR for early assessment of renal function are limited, because it represents the overall function of both kidneys, and the kidneys have a strong compensatory ability in the early stage [7]. Previous study also showed that most chronic kidney disease patients with proteinuria less than $1 \mathrm{~g} / 24 \mathrm{~h}$ can be classified as low-risk and can only be treated through outpatient follow-up, while patients with high-risk (proteinuria greater than $1 \mathrm{~g} / 24 \mathrm{~h}$ ) need to be registered and treated through inpatient management [8]. However, the measurements of proteinuria need to collect $24 \mathrm{~h}$ urine, which is inconvenient, especially for outpatients.

With the development of magnetic resonance imaging (MRI) equipment hardware and software, diffusion weighted imaging (DWI) is increasingly used in the evaluation of diseases in abdominal organs [9-11].
Conventional DWI calculates the apparent diffusion coefficient (ADC) to quantify the random motion of water molecules in biological tissues, but this monoexponential model assumes that water molecules follow a Gaussian statistical distribution [12]. However, the cell membranes and intracellular organelles of the tissues in vivo will cause the non-Gaussian diffusion of water molecule, resulting in ADC not being able to accurately reflect the true diffusion of water molecules in the complex microenvironment. Based on this background, diffusion kurtosis imaging (DKI), which include multiple $b$-values and ultra-high $b$-values $\left(>1000 \mathrm{~s} / \mathrm{mm}^{2}\right)$, is introduced as a non-Gaussian diffusion model to evaluate the true structural information of the tissue [13]. Previous study demonstrated that DKI can provide quantitative parameters such as mean kurtosis (MK), mean diffusivity (MD) to quantify the deviation of water diffusion from Gaussian distribution [14]. Previous studies on breast cancer, rectal cancer, cervical cancer have shown the potential of DKI to provide more accurate water molecular diffusion information in vivo, and it can more accurately evaluate the stages of tumors [15-17]. Recently, a study demonstrated that DKI can evaluate renal fibrosis in patients with IgAN [18]. However, this study only applied renal cortex DKI parameters and did not have control group.

The purpose of this study was to evaluate the clinical and pathological characteristics of patients with IgAN by using the renal cortex and medulla DKI parameters compared with conventional DWI.

\section{Materials and methods \\ Patients}

The ethics committee of our hospital approved this prospective study and written informed consent was obtained from all participants. All patients from the Department of Nephrology who were suspected of having IgAN underwent MRI scans before renal biopsy. We enrolled 54 patients with chronic kidney disease (CKD), forty of whom were pathologically confirmed as IgAN from December 2020 to July 2021. Twelve patients with IgAN were excluded according to the following criteria: 1 , poor image quality $(n=3) ; 2$, incomplete clinical data $(n=2) ; 3$, large renal mass lesions $(n=4) ; 4$, severe renal parenchyma atrophy $(n=2) ; 5$, polycystic kidney disease $(n=1)$. Finally, twenty-eight patients with pathologically confirmed IgAN were included in this study (15 male, 13 female; mean age, $38.61 \pm 10.12$ years; range, 22-58 years). We subsequently included 14 healthy volunteers of similar age and gender without kidney disease or other diseases that affect renal function $(6$ male, 8 female; mean age, $44.86 \pm 13.65$ years; range, 27-66 years). Patients were divided into three groups 


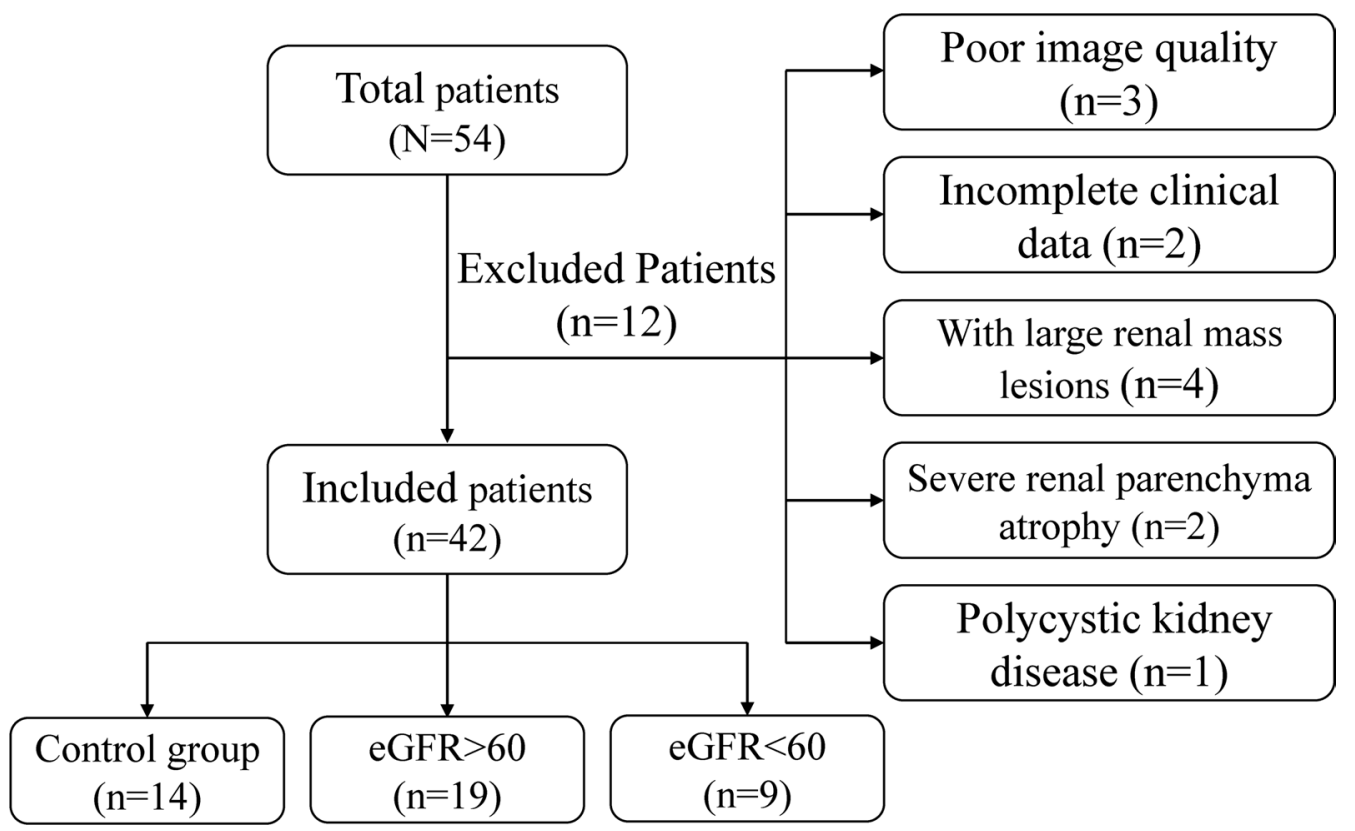

Fig. 1 Flowchart of the study population

according to their eGFR (Group1, healthy volunteers; Group2, IgAN patients with eGFR $>60 \mathrm{~mL} / \mathrm{min} / 1.73 \mathrm{~m}^{2}$; Group3, IgAN patients with eGFR $<60 \mathrm{~mL} / \mathrm{min} / 1.73 \mathrm{~m}^{2}$ ). Inclusion criteria are presented in Fig. 1.

\section{Laboratory parameters}

All patients underwent intravenous blood sampling to assess renal function, including serum creatinine $(\mathrm{Scr})$, uric acid, blood urea nitrogen (BUN). The normal values of Scr, uric acid, and BUN are 59-104 umol/L, 202-416 umol/L, 3.1-8.0 $\mathrm{mmol} / \mathrm{L}$, respectively. The eGFR was calculated based on the modification of diet in renal disease (MDRD) formula [19]: completed by a nephrologist with 15 years of clinical experience in our hospital. We calculated the glomerular, tubulointerstitial, and vascular lesion scores by using Katafuchi semi-quantitative standards [21]. The glomerular lesion scores ranged from 0 to 12 points including glomerular cell proliferation ( $0-4$ points), segmental lesions (0-4 points), and glomerular sclerosis ( $0-4$ points). The tubulointerstitial lesion scores ranged from 0 to 9 points including interstitial fibrosis $(0-3$ points), tubular atrophy (0-3 points), and interstitial inflammatory cell infiltration (0-3 points). The vascular lesion scores ranged from 0 to 6 points including vascular thickening $(0-3$ points), and hyaline degeneration ( $0-3$ points). The

$$
\operatorname{eGFR}\left(\mathrm{mL} / \mathrm{min} / 1.73 \mathrm{~m}^{2}\right)=186 \times(\mathrm{Scr})^{-1.154} \times(\text { Age })^{-0.203} \times(0.742 \text { if Female }) \times(1.210 \text { if African American })
$$

All blood biochemical tests were performed within 1 week of renal biopsy and MRI.

\section{Pathology parameters}

All patients underwent ultrasound-guided renal biopsy within 1-2 days after completing the renal MR examinations and the biopsy site was the lower pole of the right kidney in our study. All kidney specimens were obtained by percutaneous ultrasound-guided kidney biopsy and sent for immunofluorescence, optical microscopy, and electron microscopy pathological evaluation. This analysis process is similar to the previous study [20] and was details of the pathology scores are shown in Table 1.

\section{MRI acquisition}

All MRI examinations were completed within 1-2 days before the kidney biopsy and all patients including volunteers were informed fast for $8 \mathrm{~h}$ and water for $4 \mathrm{~h}$ before the MR examinations. All patients will be informed of safety precautions and relieve their nervousness before the examination and perform breathing training according to our instructions. The MRI examinations were performed on a 3T scanner (MAGNETOM Skyra, Siemens Healthcare, Erlangen, Germany) 
Table 1 A semi-quantitative standard for calculating the scores of glomerular, tubular interstitial and vascular lesions

\begin{tabular}{|c|c|c|c|c|c|c|c|c|}
\hline \multirow[t]{2}{*}{ Scores } & \multicolumn{3}{|c|}{ Glomerular lesion score } & \multicolumn{3}{|c|}{ Tubulointerstitial lesion score } & \multicolumn{2}{|c|}{ Vascular lesion score } \\
\hline & $\begin{array}{l}\text { Glomerular cell } \\
\text { proliferation (\%) }\end{array}$ & $\begin{array}{l}\text { Segmental } \\
\text { lesions (\%) }\end{array}$ & $\begin{array}{l}\text { Glomerular } \\
\text { sclerosis (\%) }\end{array}$ & $\begin{array}{l}\text { Interstitial } \\
\text { fibrosis (\%) }\end{array}$ & $\begin{array}{l}\text { Tubular } \\
\text { atrophy (\%) }\end{array}$ & $\begin{array}{l}\text { Interstitial } \\
\text { inflammatory cell } \\
\text { infiltration (\%) }\end{array}$ & $\begin{array}{l}\text { Vascular } \\
\text { thickening (\%) }\end{array}$ & $\begin{array}{l}\text { Hyaline } \\
\text { degeneration (\%) }\end{array}$ \\
\hline 1 & $\leq 25$ & $\leq 10$ & $\leq 10$ & $\leq 25$ & $\leq 25$ & $\leq 25$ & $\leq 10$ & $\leq 25$ \\
\hline 2 & $25-50$ & $10-25$ & $10-25$ & $25-50$ & $25-50$ & $25-50$ & $10-25$ & $25-50$ \\
\hline 3 & $50-75$ & $25-50$ & $25-50$ & $\geq 50$ & $\geq 50$ & $\geq 50$ & $\geq 25$ & $\geq 50$ \\
\hline 4 & $\geq 75$ & $\geq 50$ & $\geq 50$ & NA & NA & NA & NA & NA \\
\hline
\end{tabular}

NA, not applicable

with an eighteen-channel phased-array coil. Conventional coronal T2WI, axial T1WI, T2WI, and a prototype DKI-DWI sequences were performed. DKI-DWI applied a single-shot echoplanar imaging (EPI) sequence during free-breathing and combined with reduced field-of-view (ZOOMit) with tilted excitation plane in axial orientation [22]. The parameters were as follows: $\mathrm{FOV}=288 \times 125 \mathrm{~mm}$, slice thickness $=5.0 \mathrm{~mm}$, Matrix $=120 \times 120, \mathrm{TR}=7700 \mathrm{~ms}, \mathrm{TE}=72 \mathrm{~ms}$. We applied fat saturation technology to reduce chemical shift artifacts and applied a 4-directional diffusion-weighting gradient that included $5 b$-values $(0,500,1000,1500$, 2000). The acquisition time ranged from 4 to $5 \mathrm{~min}$, varying based on the number of slices.

\section{Image analysis}

We transferred the original images from the workstation to our hard disk and used the post-processing software offline provided by MR Body Diffusion Toolbox v1.4.0 (Siemens Healthcare, Erlangen, Germany) to obtain DKIDWI parameters (MK, MD) and ADC values. Two radiologists with 8 and 18 years of experience in abdominal imaging, without knowing the clinical information of the patients, delineated the bilateral renal cortex and medullary regions of interest (ROIs) at the largest level through the renal hilum. Cortical ROIs $\left(4.51 \pm 0.59 \mathrm{~cm}^{2}\right)$ were drawn along the outline of the kidneys avoiding large vessels, fat, and cysts. Three medullary ROIs $(0.61 \pm 0.02$ $\mathrm{cm}^{2}$ ) were delineated on each kidney by using the T2WI anatomical images as a reference. The placement of cortical and medullary ROIs is shown in Fig. 2, which shows the MRI image of healthy volunteers with $\mathrm{eGFR}=109.5 \mathrm{~mL} / \mathrm{min} / 1.73 \mathrm{~m}^{2}$. Figures 3 and 4 show the MRI and pathological images of the IgAN patients with eGFR $=77.4 \mathrm{~mL} / \mathrm{min} / 1.73 \mathrm{~m}^{2}$ and eGFR $=18.7 \mathrm{~mL} /$ $\min / 1.73 \mathrm{~m}^{2}$, respectively. The values of cortical MK, $\mathrm{MD}$, and ADC in Fig. 2 are $0.547,3.149 \times 10^{-3} \mathrm{~mm}^{2} / \mathrm{s}$, and $1.948 \times 10^{-3} \mathrm{~mm}^{2} / \mathrm{s}$, respectively. The values of medullary MK, MD, and ADC in Fig. 2 are 0.562, $2.534 \times 10^{-3}$ $\mathrm{mm}^{2} / \mathrm{s}$, and $1.755 \times 10^{-3} \mathrm{~mm}^{2} / \mathrm{s}$, respectively. The values of cortical MK, MD, and ADC in Fig. 3 are 0.576, $2.897 \times 10^{-3} \mathrm{~mm}^{2} / \mathrm{s}$, and $1.821 \times 10^{-3} \mathrm{~mm}^{2} / \mathrm{s}$, respectively. The values of medullary $\mathrm{MK}, \mathrm{MD}$, and $\mathrm{ADC}$ in Fig. 3 are $0.581,2.710 \times 10^{-3} \mathrm{~mm}^{2} / \mathrm{s}$, and $1.711 \times 10^{-3}$

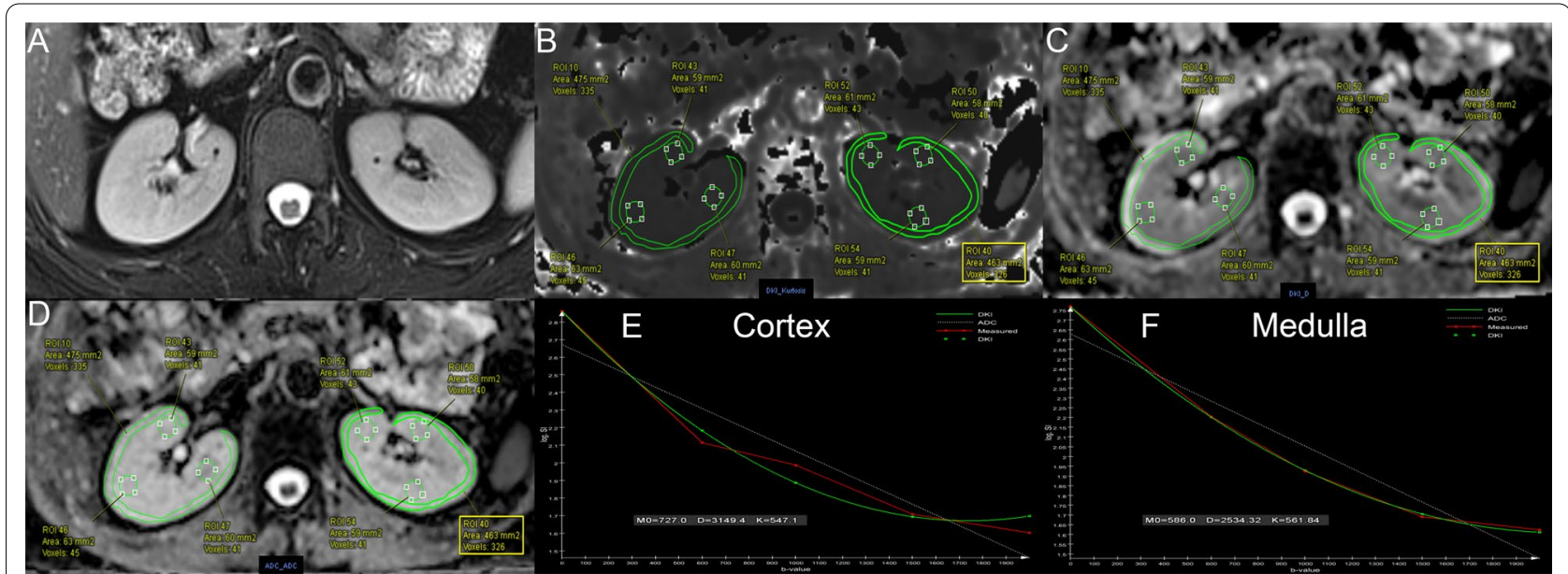

Fig. 2 Respective MRI images of healthy volunteers with eGFR=109.5 mL/min/1.73 $\mathrm{m}^{2}$. A-F axial T2-weighted image, MK, MD, ADC, cortex DKI fit, medulla DKI fit, respectively 


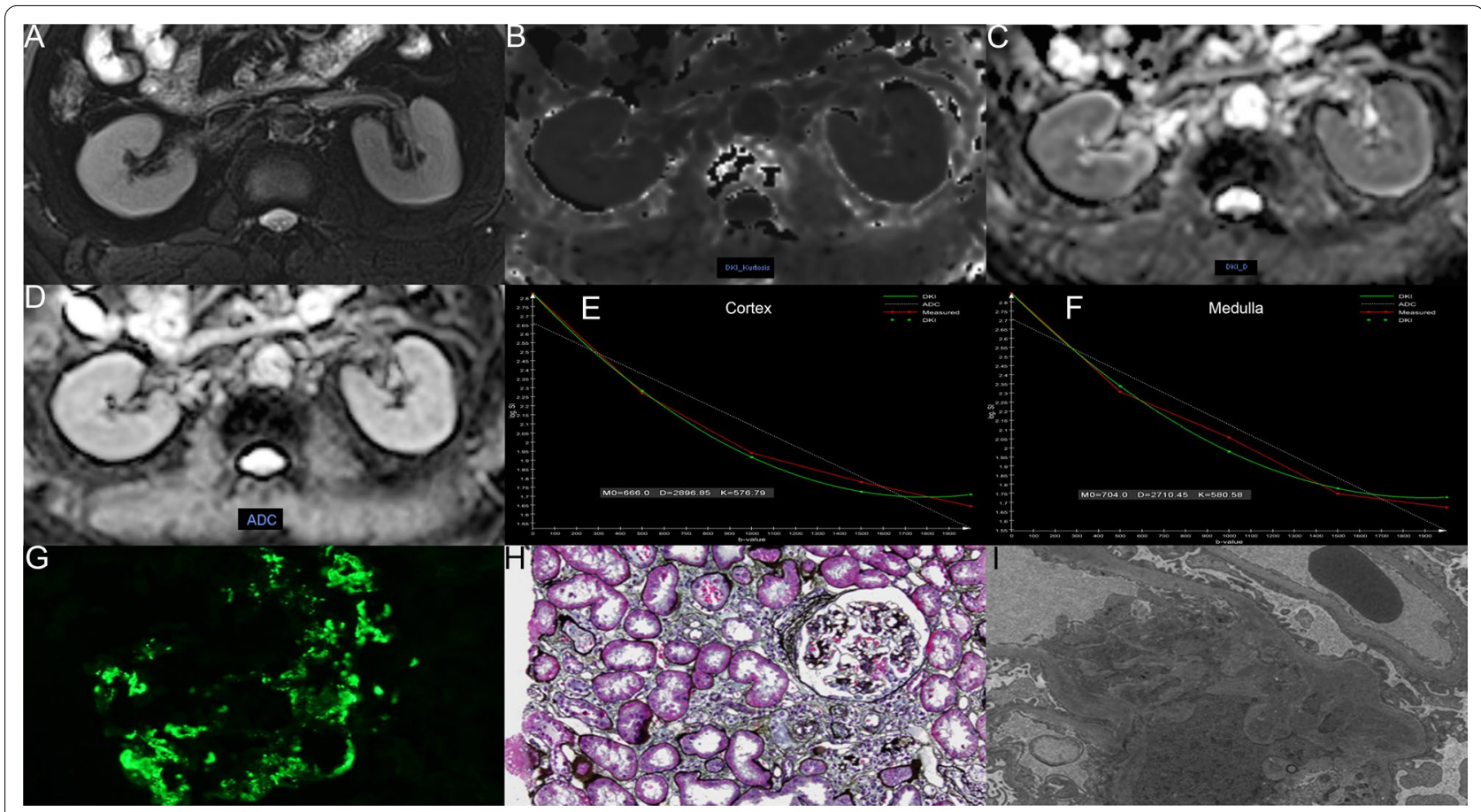

Fig. 3 Respective MRI and pathological images of the IgAN patients with eGFR=77.4 mL/min/1.7 3m². A-I axial T2-weighted image, MK, MD, ADC, cortex DKI fit, medulla DKI fit, immunofluorescence, light microscopy, and electron microscopy, respectively. The pathological result of this patient is MOEOSIT1C1

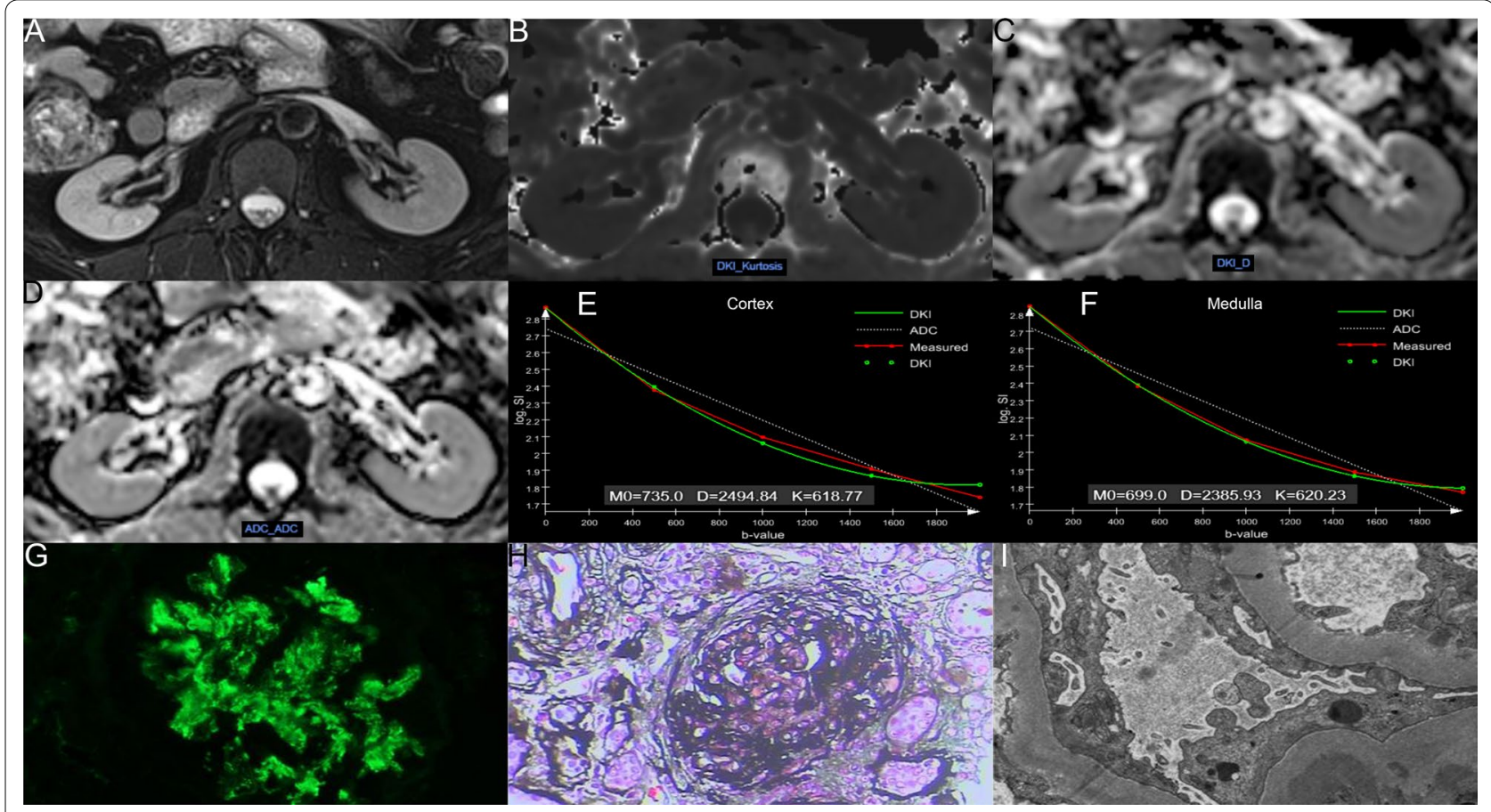

Fig. 4 Respective MRI and pathological images of the IgAN patients with eGFR $=18.7 \mathrm{~mL} / \mathrm{min} / 1.73 \mathrm{~m}^{2}$. A-I axial T2-weighted image, MK, MD, ADC, cortex DKI fit, medulla DKI fit, immunofluorescence, light microscopy, and electron microscopy, respectively. The pathological result of this patient is MOE1S1T2CO 
$\mathrm{mm}^{2} / \mathrm{s}$, respectively. The values of cortical MK, MD, and ADC in Fig. 4 are $0.618,2.494 \times 10^{-3} \mathrm{~mm}^{2} / \mathrm{s}$, and $1.624 \times 10^{-3} \mathrm{~mm}^{2} / \mathrm{s}$, respectively. The values of medullary MK, MD, and ADC in Fig. 4 are 0.620, $2.385 \times 10^{-3}$ $\mathrm{mm}^{2} / \mathrm{s}$, and $1.589 \times 10^{-3} \mathrm{~mm}^{2} / \mathrm{s}$, respectively. ADC values were calculated by using a monoexponential model with b-values of 0 and $1000 \mathrm{~s} / \mathrm{mm}^{2}$ according to the following equation [23]:

$$
S b=S 0 \times e^{\left(-b \times A D C_{m o n}\right)}
$$

where $S b$ is the signal at a given $b$ value $\left(b=1000 \mathrm{~s} / \mathrm{mm}^{2}\right.$ in our study), $S 0$ is the signal when $b=0 \mathrm{~s} / \mathrm{mm}^{2}$.

MK and MD were calculated with all of $b$ values $\left(0-2000 \mathrm{~s} / \mathrm{mm}^{2}\right)$ by using the following equation [24]:

$$
S b=S 0 \times e^{(-b \times D+1 / 6 \times b 2 \times D 2 \times K)}
$$

where $S b$ is the signal at a particular $b$ value, $S 0$ is the signal when $b=0 \mathrm{~s} / \mathrm{mm}^{2}$. $D$ represents the ADC analog adjusted for non-Gaussian diffusion behavior and the unit is $\mathrm{mm}^{2} / \mathrm{s}$. $K$ represents the excess kurtosis relative to a monoexponential fit and has no unit. It is 0 in tissues with complete Gaussian diffusion and increases with greater deviation from the Gaussian pattern.

\section{Statistical analysis}

All statistical analyses were performed on SPSS (version 22 , Chicago, IL) and the values of $p<0.05$ were considered statistically significant. We used Shapiro-Wilk test to evaluate the normality of data distribution $(p \geq 0.05$ demonstrates normal distribution). Normally distributed variables were expressed as means \pm standard deviations. One-way analysis of variance (ANOVA) was used to compare the differences of clinical and DKI parameters among the three groups. The least-significant difference (LSD) test was used to compare the differences between any two groups. The intraclass correlation coefficients (ICCs) were employed to evaluate the interobserver agreements (0.81-1.00, excellent agreement; 0.61-0.80, moderate agreement; $0.21-0.40$, fair agreement; $0.00-$ 0.20 , poor agreement). Pearson product-moment correlation was used to evaluate the relationships between the diffuse parameters and clinical parameters and Spearman's rank correlation was used to evaluate the relationships between the diffuse parameters and pathological scores (The absolute value of the correlation coefficient below 0.3 represented no linear correlation, $0.3-0.5$ was low correlation, $0.5-0.8$ was moderate correlation, and above 0.8 was highly correlated). Receiver operating characteristic (ROC) curves were used to evaluate the diagnostic performance of DKI parameters for differentiating Group2 from Group1, or Group3.

\section{Results}

\section{Clinical characteristics}

Fourteen healthy volunteers and 28 IgAN patients were included in the statistical analysis. There were no significant differences in sex $(p=0.798)$ among the three groups. However, the age between the Group1 and Group2 showed significant difference $(p=0.038)$, and the age of Group2 is significantly smaller than that of Group1. The values of eGFR, Scr, uric acid, and BUN showed significant differences among the three groups (all $p<0.001$ ). Furthermore, the values of Scr, uric acid, and BUN increase with the decrease in eGFR. The details of these clinical parameters are shown in Table 2.

\section{Interobserver agreement}

The interobserver agreements of the renal cortex and medulla $\mathrm{MK}, \mathrm{MD}$, and $\mathrm{ADC}$ between the two radiologists are excellent (all ICC $>0.80$ ). The results showed that the reproducibility of the diffuse parameters was excellent, and it was suitable for repeated measurements for long-term longitudinal follow-up of patients with IgAN. Therefore, we randomly selected the measurement results of one radiologist for the statistical analysis. The ICC values and $95 \%$ confidence intervals $(95 \% \mathrm{CI})$ of the renal cortex and medulla $\mathrm{MK}, \mathrm{MD}$, and $\mathrm{ADC}$ are present in Table 3.

\section{Comparisons of the diffuse parameters between different groups}

Only $\mathrm{MK}_{\text {Cortex }}$ and $\mathrm{ADC}_{\text {Cortex }}$ showed significant differences between the Group1 and Group2 $(p=0.002$, $p=0.017$, respectively). $\mathrm{MK}_{\text {Cortex }}, \mathrm{MD}_{\text {Cortex }}, \mathrm{ADC}_{\text {Cortex }}$, $\mathrm{MK}_{\text {Medulla, }}$, and $\mathrm{ADC}_{\text {Medulla }}$ showed significant differences between Group1 and IgAN patients with eGFR $<60 \mathrm{~mL} /$ $\min / 1.73 \mathrm{~m}^{2}(p<0.001, p<0.001, p<0.001, p<0.001$, and $p=0.010$, respectively). There were also significant differences in $\mathrm{MK}_{\text {Cortex }}, \mathrm{MD}_{\text {Cortex }}, \mathrm{ADC}_{\text {Cortex }}, \mathrm{MK}_{\text {Medulla }}$, and $\mathrm{ADC}_{\text {Medulla }}$ between Group3 and Group2 $(p<0.001$, $p<0.001, p=0.006, p<0.001$, and $p=0.010$, respectively). $\mathrm{MD}_{\text {Medulla }}$ showed no significant differences between Group1 and Group3, or Group2 and Group3. These results are present in Table 2 and Fig. 5.

\section{Correlations between diffuse parameters and clinicopathological parameters}

$\mathrm{MK}_{\text {Cortex }}$ and $\mathrm{MK}_{\text {medulla }}$ showed moderate correlations with CKD stages, eGFR, Scr, uric acid, and BUN. $\mathrm{MD}_{\text {Cortex }}$ showed low correlations with CKD stages, eGFR, Scr, uric acid, and BUN. MD $D_{\text {Medulla }}$ showed no significant correlations with clinical parameters. $\mathrm{ADC}_{\text {cortex }}$ showed low to moderate correlations with CKD stages, eGFR, Scr, uric acid, and BUN. ADC Medulla 
Table 2 Baseline clinical data and diffusional kurtosis imaging (DKI) parameters

\begin{tabular}{|c|c|c|c|c|c|c|}
\hline Characteristics & Control group & eGFR $\geq 60 \mathrm{~mL} / \mathrm{min}$ & $\mathrm{eGFR}<60 \mathrm{~mL} / \mathrm{min}$ & $P^{a}$ & $P^{\beta}$ & $P^{r}$ \\
\hline \multicolumn{7}{|l|}{ Clinical data } \\
\hline No. of patients & 14 & 19 & 9 & & & \\
\hline Males/females & $6 / 8$ & $10 / 9$ & $5 / 4$ & 0.579 & 0.552 & 0.885 \\
\hline Age, year & $44.86 \pm 13.65$ & $36.37 \pm 9.49$ & $43.33 \pm 10.28$ & 0.038 & 0.752 & 0.132 \\
\hline $\mathrm{eGFR}, \mathrm{mL} / \mathrm{min} / 1.73 \mathrm{~m}^{2}$ & $106.47 \pm 9.79$ & $89.20 \pm 22.62$ & $35.53 \pm 13.82$ & 0.008 & $<0.001$ & $<0.001$ \\
\hline $\mathrm{SCr}, \mu \mathrm{mol} / \mathrm{L}$ & $58.00 \pm 16.68$ & $82.79 \pm 20.21$ & $190.11 \pm 49.45$ & 0.016 & $<0.001$ & $<0.001$ \\
\hline Uric acid, mg/dL & $247.71 \pm 106.26$ & $326.66 \pm 90.67$ & $430.88 \pm 91.31$ & 0.025 & $<0.001$ & 0.011 \\
\hline $\mathrm{BUN}, \mathrm{mg} / \mathrm{dL}$ & $4.11 \pm 1.61$ & $5.74 \pm 1.38$ & $9.18 \pm 2.98$ & 0.019 & $<0.001$ & $<0.001$ \\
\hline \multicolumn{7}{|l|}{ DKI metrics } \\
\hline $\mathrm{MK}_{\text {Cortex }}$ & $0.536 \pm 0.011$ & $0.571 \pm 0.028$ & $0.629 \pm 0.053$ & 0.002 & $<0.001$ & $<0.001$ \\
\hline$M D_{\text {Cortex }}$ & $3.031 \pm 0.320$ & $2.963 \pm 0.235$ & $2.553 \pm 0.207$ & 0.462 & $<0.001$ & $<0.001$ \\
\hline$A D C_{\text {Cortex }}$ & $1.937 \pm 0.142$ & $1.836 \pm 0.105$ & $1.702 \pm 0.084$ & 0.017 & $<0.001$ & 0.006 \\
\hline $\mathrm{MK}_{\text {Medulla }}$ & $0.564 \pm 0.030$ & $0.581 \pm 0.027$ & $0.633 \pm 0.025$ & 0.100 & $<0.001$ & $<0.001$ \\
\hline $\mathrm{MD}_{\text {Medulla }}$ & $2.592 \pm 0.363$ & $2.691 \pm 0.319$ & $2.459 \pm 0.198$ & 0.378 & 0.327 & 0.076 \\
\hline$A D C_{\text {Medulla }}$ & $1.744 \pm 0.101$ & $1.737 \pm 0.086$ & $1.632 \pm 0.113$ & 0.843 & 0.010 & 0.010 \\
\hline
\end{tabular}

eGFR, estimated glomerular filtration rate; $\mathrm{SCr}$, serum creatinine; $\mathrm{BUN}$, blood urea nitrogen; $\mathrm{MK}$, mean kurtosis; $\mathrm{MD}$, mean diffusivity; $\mathrm{ADC}$, apparent diffusion coefficient

a Represents the comparison of parameters between control group and eGFR $\geq 60 \mathrm{~mL} / \mathrm{min}$

${ }^{\beta}$ Represents the comparison of parameters between control group and eGFR $<60 \mathrm{~mL} / \mathrm{min}$

${ }^{\gamma}$ Represents the comparison of parameters between eGFR $\geq 60 \mathrm{~mL} / \mathrm{min}$ and eGFR $<60 \mathrm{~mL} / \mathrm{min}$

Table 3 The interobserver agreements between two radiologists of the diffusional kurtosis imaging (DKI) metrics

\begin{tabular}{lll}
\hline Parameters & ICC & $\mathbf{9 5 \%} \mathbf{C l}$ \\
\hline $\mathrm{MK}_{\text {Cortex }}$ & 0.978 & $0.959-0.988$ \\
$\mathrm{MD}_{\text {Cortex }}$ & 0.969 & $0.942-0.983$ \\
$\mathrm{ADC}_{\text {Cortex }}$ & 0.967 & $0.939-0.982$ \\
$\mathrm{MK}_{\text {Medulla }}$ & 0.913 & $0.836-0.953$ \\
$\mathrm{MD}_{\text {Medulla }}$ & 0.924 & $0.858-0.959$ \\
ADC $_{\text {Medulla }}$ & 0.899 & $0.813-0.946$ \\
\hline
\end{tabular}

MK, mean kurtosis; MD, mean diffusivity; ADC, apparent diffusion coefficient; ICC, intraclass correlation coefficient; $\mathrm{Cl}$, confidence intervals

showed low correlations with CKD stages, eGFR, Scr. There were no significant correlations between $\mathrm{ADC}_{\text {Medulla }}$ and uric acid, or BUN. Furthermore, $\mathrm{MK}_{\mathrm{Cortex}}$ and Scr showed the highest correlation coefficient $(r=0.781, p<0.001)$. The correlation coefficients and correlation scatter plot between the diffusion parameters and clinical parameters are shown in Table 4 and Fig. 6, respectively. $\mathrm{MK}_{\mathrm{Cortex}}, \mathrm{MK}_{\text {Medulla }}$, $\mathrm{MD}_{\text {Cortex }}$, and $\mathrm{ADC}_{\text {Cortex }}$ also showed low to moderate correlations with pathology score, such as total score, glomerular lesion score, tubulointerstitial lesion score, interstitial fibrosis, tubular atrophy, and interstitial inflammatory cell infiltration. $\mathrm{MD}_{\text {Medulla }}$ only showed low negative correlations with total score, glomerular lesion score, tubulointerstitial lesion score, and tubular atrophy. $\mathrm{ADC}_{\text {Medulla }}$ showed no correlation with glomerular lesion score. The highest correlation coefficients between the diffusion parameters and pathology scores were $\mathrm{MK}_{\text {Cortex }}$ and tubular atrophy $(r=0.596$, $p=0.001)$. The correlation coefficients and correlation scatter plot between the diffusion parameters and clinical parameters are shown in Table 4 and Fig. 7, respectively.

\section{Diagnostic performance of the diffusion parameters}

We applied ROC curves analysis to evaluate the diagnostic performance of the different diffusion parameters for differentiating Group2 from Group1 or Group3. The biggest area under the curve (AUC) for differentiating Group2 from Group1 was $\mathrm{MK}_{\text {Cortex }}$ (AUC, 0.923, 95\% CI $0.775-0.987$ ) with sensitivity of $84.21 \%$, specificity of $100 \%$, and a cut-off value of 0.552 . Both $\mathrm{MD}_{\text {Cortex }}$ and $\mathrm{MK}_{\text {Medulla }}$ showed excellent ability for differentiating Group2 from Group3 (AUC, 0.924, 95\% CI, 0.759-0.990; AUC, 0.923, 95\% CI 0.753-0.990, respectively) with sensitivity of $100 \%, 88.89$; specificity of $68.42 \%, 88.89$; and a cut-off value of $2.891 \mathrm{~mm}^{2} / \mathrm{s}$, and 0.552 , respectively. The results of the ROC analysis of the diffusion parameters are shown in Table 5 and Fig. 8. 

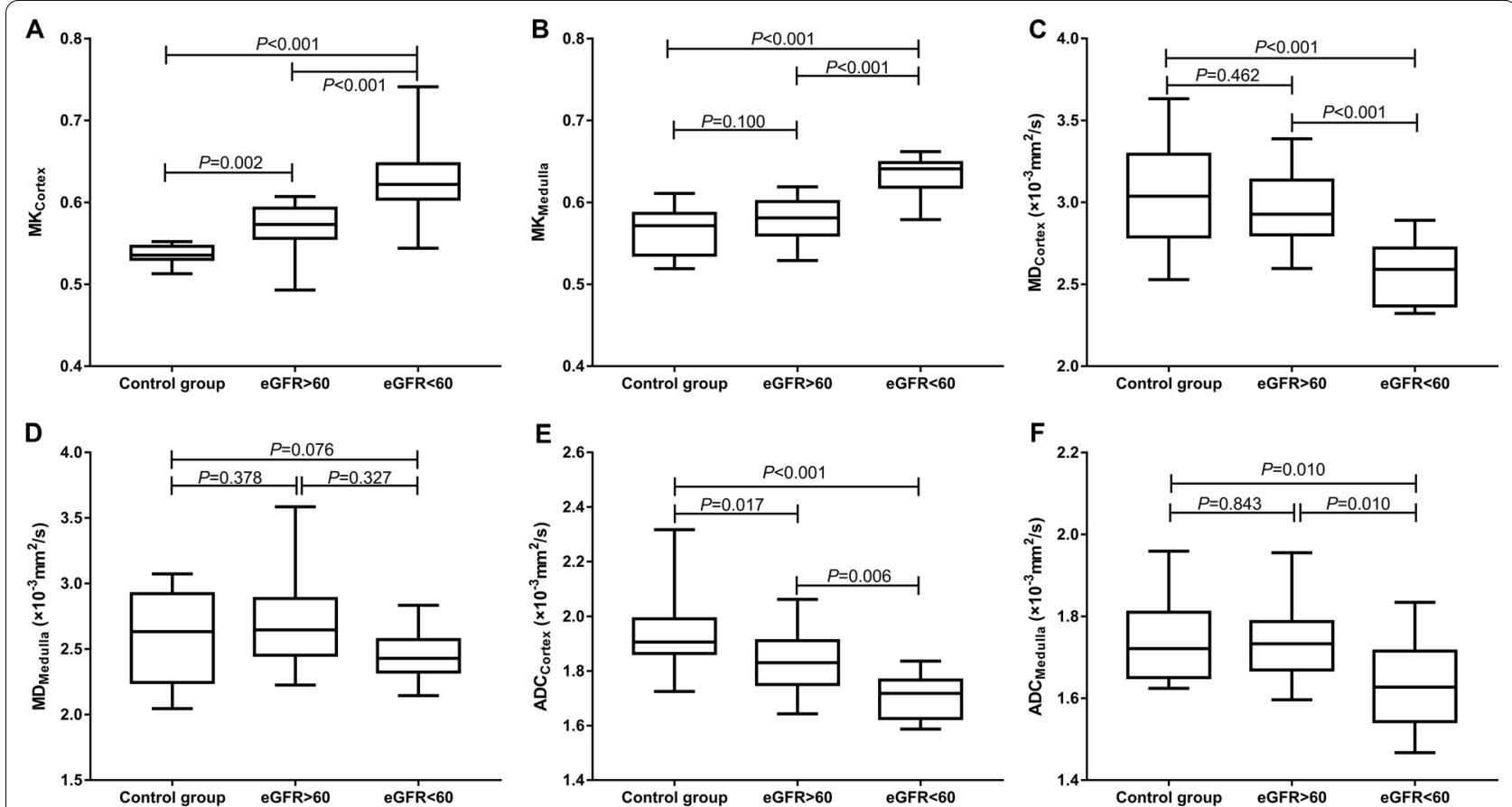

Fig. 5 Comparison of cortical and medullary diffusion parameters between the three groups

Table 4 Correlations between the diffusional kurtosis imaging (DKI) metrics and clinicopathological data

\begin{tabular}{|c|c|c|c|c|c|c|c|c|c|c|c|c|}
\hline & \multicolumn{4}{|l|}{ MK } & \multicolumn{4}{|l|}{ MD } & \multicolumn{4}{|l|}{$A D C$} \\
\hline & \multicolumn{2}{|l|}{ Cortex } & \multicolumn{2}{|c|}{ Medulla } & \multicolumn{2}{|l|}{ Cortex } & \multicolumn{2}{|l|}{ Medulla } & \multicolumn{2}{|l|}{ Cortex } & \multicolumn{2}{|l|}{ Medulla } \\
\hline & $r$ & $P$ & $r$ & $P$ & $r$ & $P$ & $r$ & $P$ & $r$ & $P$ & $r$ & $P$ \\
\hline CKD stages & 0.749 & $<0.001$ & 0.686 & $<0.001$ & -0.499 & 0.001 & -0.092 & 0.563 & -0.635 & $<0.001$ & -0.419 & 0.006 \\
\hline eGFR & -0.753 & $<0.001$ & -0.662 & $<0.001$ & 0.470 & 0.002 & 0.154 & 0.331 & 0.572 & $<0.001$ & 0.381 & 0.013 \\
\hline $\mathrm{SCr}$ & 0.781 & $<0.001$ & 0.752 & $<0.001$ & -0.485 & 0.001 & -0.135 & 0.394 & -0.606 & $<0.001$ & -0.440 & 0.004 \\
\hline Uric-acid & 0.485 & 0.001 & 0.496 & 0.001 & -0.397 & 0.009 & -0.180 & 0.253 & -0.425 & 0.005 & -0.224 & 0.153 \\
\hline BUN & 0.730 & $<0.001$ & 0.587 & $<0.001$ & -0.322 & 0.038 & -0.122 & 0.441 & -0.400 & 0.009 & -0.296 & 0.057 \\
\hline Total score & 0.516 & 0.005 & 0.437 & 0.023 & -0.506 & 0.006 & -0.410 & 0.030 & -0.532 & 0.004 & -0.251 & 0.197 \\
\hline Glomerular lesion score & 0.497 & 0.007 & 0.430 & 0.025 & -0.509 & 0.006 & -0.398 & 0.036 & -0.442 & 0.018 & -0.273 & 0.159 \\
\hline Tubulointerstitial lesion score & 0.548 & 0.003 & 0.499 & 0.008 & -0.471 & 0.011 & -0.398 & 0.036 & -0.541 & 0.003 & -0.261 & 0.179 \\
\hline Vascular lesion score & 0.135 & 0.493 & 0.177 & 0.378 & -0.130 & 0.508 & -0.094 & 0.634 & -0.219 & 0.262 & -0.094 & 0.635 \\
\hline Interstitial fibrosis & 0.489 & 0.008 & 0.545 & 0.003 & -0.526 & 0.004 & -0.269 & 0.166 & -0.513 & 0.005 & -0.173 & 0.379 \\
\hline Tubular atrophy & 0.596 & 0.001 & 0.536 & 0.004 & -0.487 & 0.009 & -0.370 & 0.053 & -0.438 & 0.020 & -0.189 & 0.334 \\
\hline Interstitial inflammatory cell infiltration & 0.576 & 0.001 & 0.482 & 0.011 & -0.316 & 0.102 & -0.287 & 0.139 & -0.546 & 0.003 & -0.245 & 0.210 \\
\hline
\end{tabular}

MK, mean kurtosis; MD, mean diffusivity; ADC, apparent diffusion coefficient

\section{Discussion}

Our study demonstrated that the non-Gaussian DKI model can effectively evaluate the clinical and pathological characteristics of IgAN, especially $\mathrm{MK}_{\text {Cortex }} \cdot \mathrm{MK}_{\text {Cortex }}$ was significantly correlated with CKD stages, interstitial fibrosis and renal tubular atrophy, and can well distinguish Group2 from Group1, or Group3.
The interobserver agreements of the renal cortex and medulla MK, MD, and ADC were excellent between the two radiologists. The results showed that the reproducibility and reliability of DKI were convincing, and it can safely, noninvasively and non-radiately carry out longterm longitudinal follow-up of IgAN patients. 

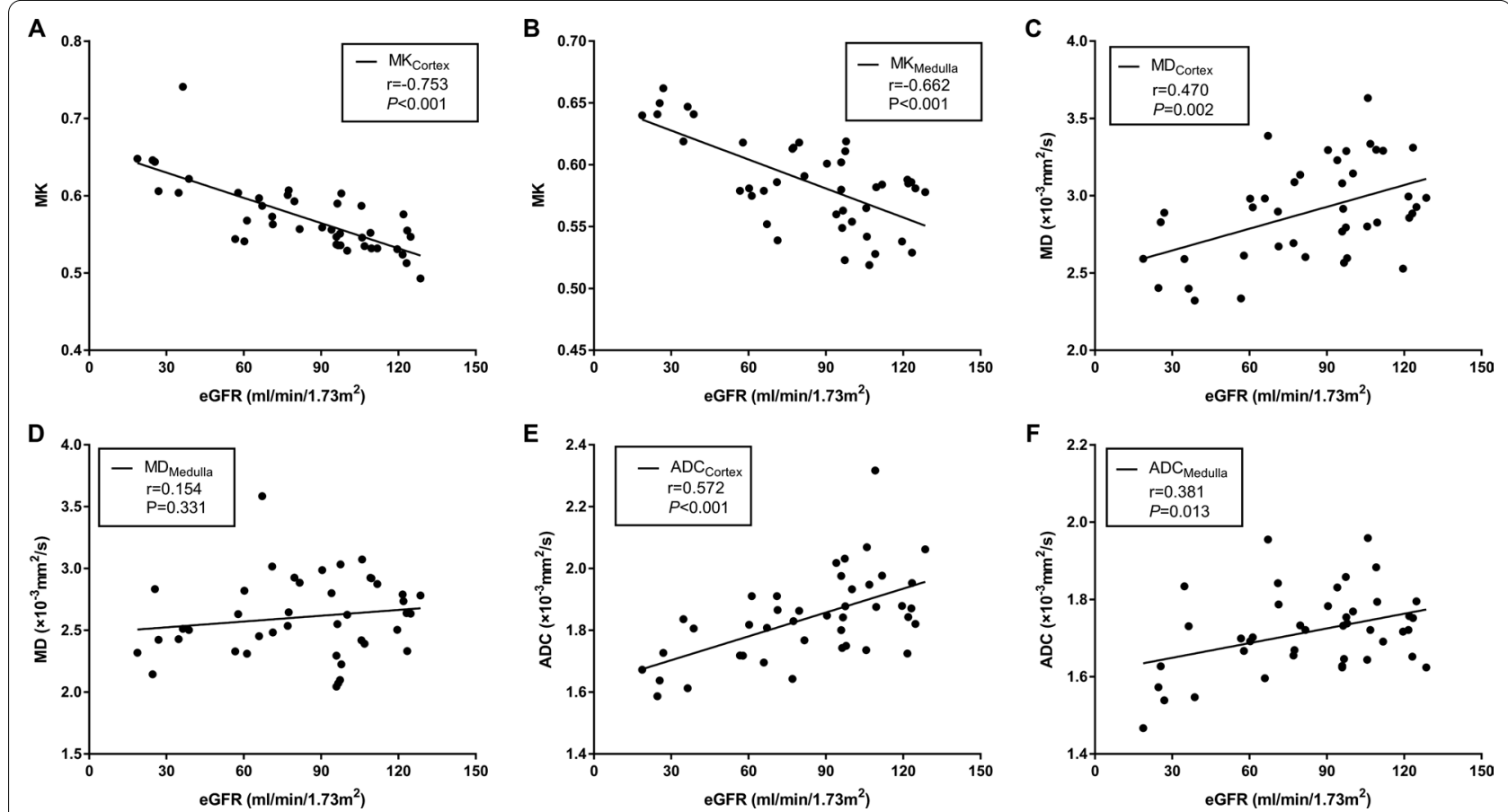

Fig. 6 Correlations between cortical and medullary diffusion parameters and eGFR
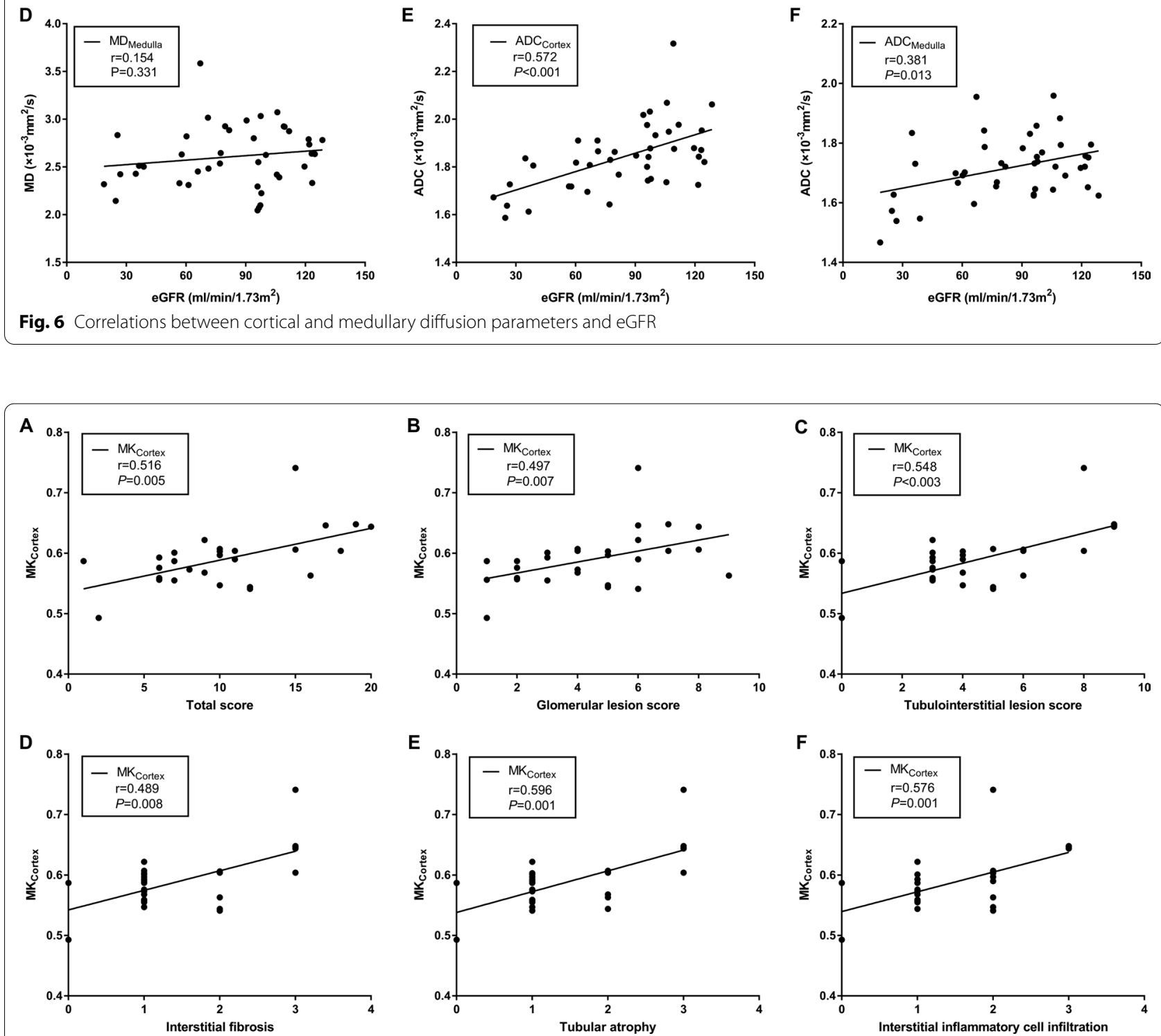

Fig. 7 Correlations between $\mathrm{MK}_{\text {Cortex }}$ and pathology score

$\mathrm{MK}_{\text {Cortex }}$ showed significant differences among the three groups, even in Group2 and Group1 in our study. However, there was no significant difference in $\mathrm{MK}_{\text {Medulla }}$ between Group1 and Group2. Furthermore, $\mathrm{MK}_{\mathrm{Cortex}}$ showed highest significant difference between the Group1 and Group2 among all the diffusion parameters 


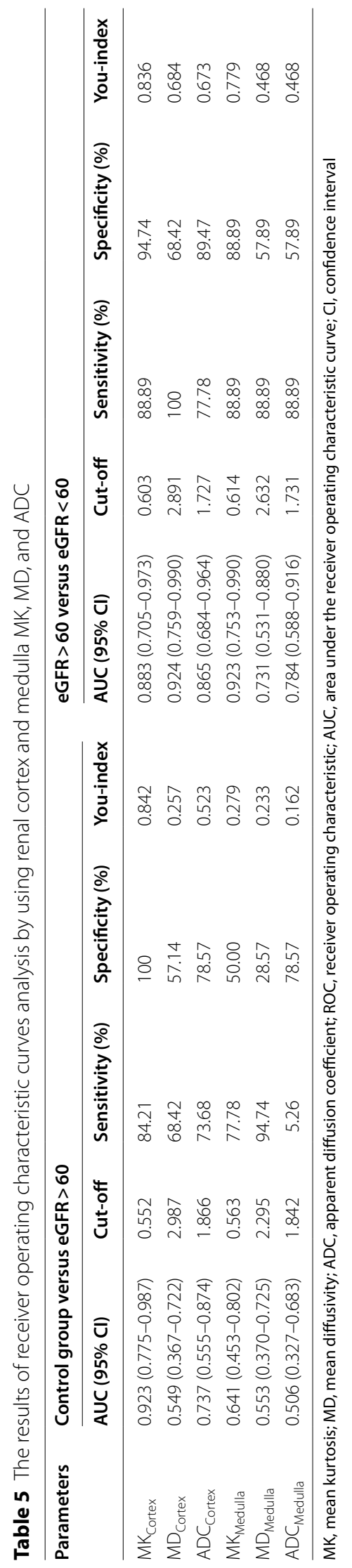



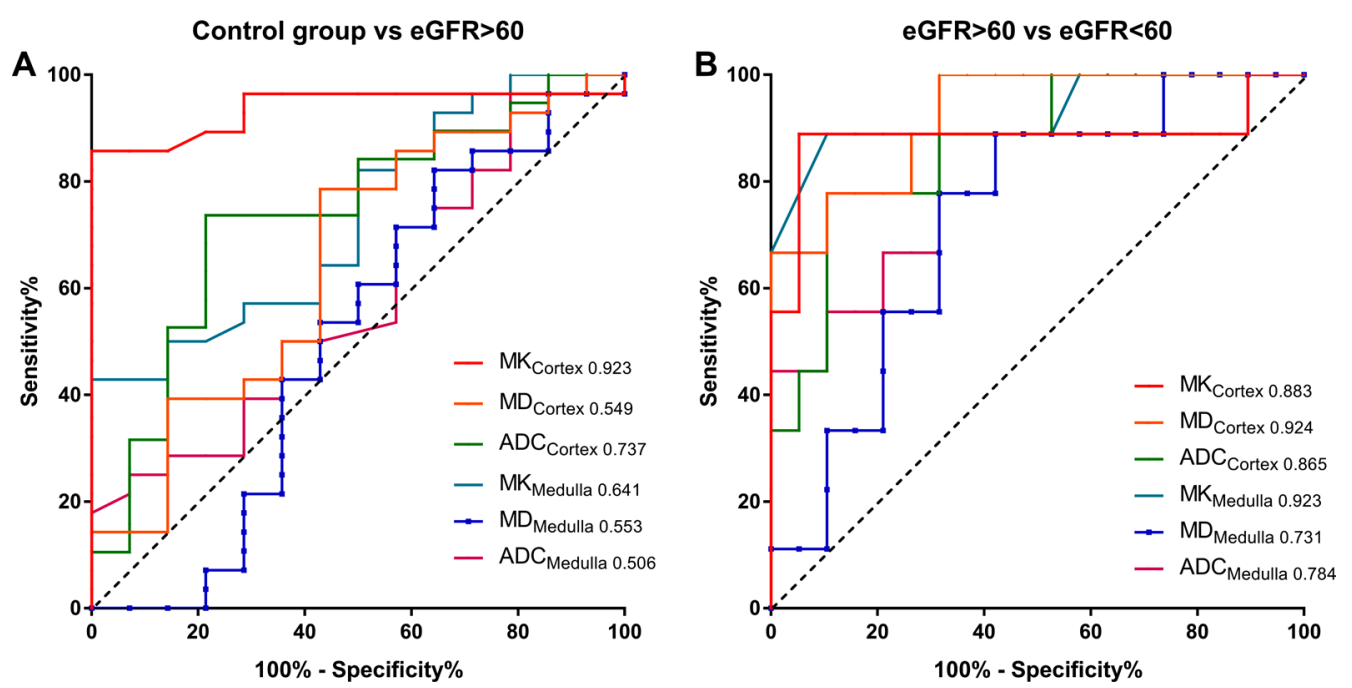

Fig. 8 The ROC curve analysis of cortical and medullary diffusion parameters to distinguish between IgAN patients with eGFR $>60 \mathrm{~mL} / \mathrm{min} / 1.73 \mathrm{~m}{ }^{2}$ and control group, or IgAN patients with eGFR $<60 \mathrm{~mL} / \mathrm{min} / 1.73 \mathrm{~m}^{2}$

in our study. The results indicated that $\mathrm{MK}_{\text {Cortex }}$ may be a reliable indicator for early evaluation of IgAN patients and this was consistent with the previous research [25], which showed that renal cortex MK values have the highest sensitivity for detecting changes of renal function in patients with CKD. The $\mathrm{MK}_{\text {Cortex }}$ increased with the decrease in eGFR and the values of $\mathrm{MK}_{\text {Medulla }}$ also had a tendency to increase as eGFR decreased. Furthermore, the values of $\mathrm{MK}_{\text {Cortex }}$ were smaller than $\mathrm{MK}_{\text {Medulla }}$ in the three groups. This may be due to the more complex microstructures of renal medulla, such as renal tubules and collecting tubules, which make the diffusion of water molecules deviate from Gaussian distribution. These results were consistent with the previous study which demonstrated the values of the renal cortex and medulla MK tended to increase with the decrease in eGFR [26]. MK represents the deviation from Gaussian distribution and previous study showed that MK of tissues represented the interaction of water molecules with cell membranes and intracellular compounds [27, 28]. Sun et al. demonstrated that the more complex the microstructure environment, the greater the values of MK [17]. Liu et al. showed that MK increased with the progression of renal function and the accumulation of collagen fibers [18]. $\mathrm{MK}_{\mathrm{Cortex}}$ and $\mathrm{MK}_{\text {Medulla }}$ were not only significantly related to clinical indicators such as eGFR, CKD stages, and Scr, but also significantly related to the glomerular lesion score, and tubulointerstitial lesion score in our study. The results were similar to previous studies [29]. This may be due to deterioration of renal function, leading to glomerular sclerosis, glomerular cell proliferation, and interstitial fibrosis, which will increase the complexity of the renal parenchymal structure and cause the diffusion of water molecules to deviate from the Gaussian distribution. MK represented the complexity of the microenvironment, which will cause the values of MK to increase with decreased renal function and increased pathological scores.

MD is another parameter of DKI, which represents the corrected diffusion coefficient of ADC under non-Gaussian conditions [30]. There was no significant difference in $\mathrm{MD}_{\text {Cortex }}$ between Group1 and Group2. $\mathrm{MD}_{\text {Cortex }}$ showed significant differences between Group3 and Group1, or Group2. The results showed that $\mathrm{MD}_{\text {Cortex }}$ was not sensitive to early changes in IgAN. Zhou et al. showed that MD can also discriminate early diabetic nephropathy from controls [26]. The reason for the differences may be due to the different pathological types and different research objects. However, $\mathrm{MD}_{\text {Cortex }}$ also had a tendency to decrease from Group1 to Group2 in our study. There were no significant differences in $\mathrm{MD}_{\text {Medulla }}$ among the three groups, which was similar with the previous study [18]. The values of $\mathrm{MD}_{\text {Cortex }}$ were larger than $\mathrm{MD}_{\text {Medulla }}$ in the three groups. This may be due to the more complex microstructures of renal medulla than cortex, leading to restricted diffusion of water molecules. Moreover, $\mathrm{MD}_{\text {Cortex }}$ had more diagnostic value than $\mathrm{MD}_{\text {Medulla }}$ in distinguishing Group2 from Group3 in our study. This may be due to the gradual deterioration of renal function, resulting in the gradual replacement of normal glomerular capillaries and tubular structures with extracellular matrix and fibrotic tissue [31]. The effect of this change on the medulla may be smaller than that of the cortex, which was richer in blood flow, and the diffusion of water 
molecules in the cortex was more restricted than in the medulla [25].

$\mathrm{ADC}_{\text {Cortex }}$ showed significant differences among the three groups; however, there was no significant difference in $\mathrm{ADC}_{\text {Medulla }}$ between Group1 and Group2 in our study. Both $\mathrm{ADC}_{\text {Cortex }}$ and $\mathrm{ADC}_{\text {Medulla }}$ showed significant correlations with CKD stages, glomerular lesion score, and tubulointerstitial lesion score. Previous study demonstrated that ADC was significantly correlated with split renal function [32] and Zhao et al. showed that renal ADC values were strongly related to histological measurement of fibrosis [33]. These studies showed similar results and ADC may be another excellent indicator for noninvasive evaluation of the clinical and pathological characteristics of IgAN patients.

We used ROC analysis to evaluate the diagnostic performance of the diffuse parameters. The best parameter for differentiating Group1 from Group2 was $\mathrm{MK}_{\text {Cortex }}$ with the AUC 0.923, followed by $\mathrm{ADC}_{\text {Cortex }}$ (AUC, 0.737). Furthermore, $\mathrm{MD}_{\text {Cortex }}$ (AUC, 0.924) was the best parameter for differentiating Group2 from Group3, followed by $\mathrm{MK}_{\text {Medulla }}$ (AUC, 0.923). The results were consistent with previous study which demonstrated medullary MK was the best parameter for discrimination of the early diabetic nephropathy from the controls without diabetes, followed by cortex MK [26]. These results indicated that glomerular sclerosis, glomerular cell proliferation, and interstitial fibrosis gradually replaced the renal normal structure with the progress of IgAN, causing the diffuse of water molecules to deviate from the Gaussian distribution, and the movement of water molecules was more restricted. MK and MD parameters based on DKI may be good indicators for assessing the progress of IgAN, and ADC also has a certain value in evaluating the renal function in patients with IgAN.

There were several limitations in this study. First, this was a single center research, and the number of IgAN patients were relatively small. Second, the measurement position of ROIs was inconsistent with the biopsy site. We delineated the ROIs through the largest level of the kidney hilum, and the kidney biopsy site was located at the lower pole of the right kidney. We supposed that the deviation was relatively small, because IgAN was a chronic diffuse disease that may affect the entire kidney. Third, Group1 were not age-matched to Group2, which may have a certain impact on our research. Fourth, the standardizations of the acquisition and analysis protocols related to diffusion parameters used in this study are still challenging because they are different in different institutions and different machines.

In conclusion, this study demonstrated that DKI was a feasible and reliable technique that can assess the clinical and pathological characteristics of patients with IgAN, especially cortical MK. Furthermore, DKI can provide more valuable information than conventional DWI and can provide useful information for clinical patient management, treatment, and prognosis.

\begin{abstract}
Abbreviations
ADC: Apparent diffusion coefficient; AUC: Area under the receiver operating characteristic curve; BUN: Blood urea nitrogen; DKl: Diffusion kurtosis imaging; DWI: Diffusion weighted imaging; eGFR: Estimated glomerular filtration rate; ESRD: End stage renal disease; ICC: Intraclass correlation coefficient; IgAN: Immunoglobulin A nephropathy; MD: Mean diffusivity; MK: Mean kurtosis; ROC: Receiver operating characteristic; ROI: Region of interest; Scr: Serum creatinine.
\end{abstract}

\section{Authors' contributions}

C.X. and Z.L. devised the experiment, S.L. and A.L. designed the tables and figures, G.Y. and K.H. performed the data analysis, D.H. revised the manuscript, P.L. wrote the original draft. All authors read and approved the final manuscript.

\section{Funding}

This study has received funding by the National Natural Science Foundation of China (Grant Nos. 82071889, 81771801).

Availability of data and materials

The data and materials of this article are available.

\section{Declarations}

\section{Ethics approval and consent to participate}

This educational review includes a statement on ethics approval and consent from the ethic committee of Huazhong University of Science Tongji Hospital, Tongji Medical College.

\section{Consent for publication}

All authors agree to publish the article.

\section{Competing interests}

The authors of this manuscript declare no relationships with any companies, whose products or services may be related to the subject matter of the article.

Received: 26 October 2021 Accepted: 7 January 2022

Published online: 29 January 2022

References

1. Roberts IS (2014) Pathology of IgA nephropathy. Nat Rev Nephrol 10:445-454

2. McGrogan A, Franssen CF, de Vries CS (2011) The incidence of primary glomerulonephritis worldwide: a systematic review of the literature. Nephrol Dial Transplant 26:414-430

3. Berthoux FC, Mohey H, Afiani A (2008) Natural history of primary IgA nephropathy. Semin Nephrol 28:4-9

4. Ren L, Zhang C, Pan Y, Sun J (2019) The value of serum IgA in the diagnosis, clinical and pathological evaluation of patients with IgA nephropathy found during physical examination in China. Clin Lab 65:2355-2360

5. Jiang SH, Karpe KM, Talaulikar GS (2011) Safety and predictors of complications of renal biopsy in the outpatient setting. Clin Nephrol 76:464-469

6. Cattran DC, Coppo R, Cook HT et al (2009) The Oxford classification of IgA nephropathy: rationale, clinicopathological correlations, and classification. Kidney Int 76:534-545

7. Shlipak MG, Katz R, Sarnak MJ et al (2006) Cystatin C and prognosis for cardiovascular and kidney outcomes in elderly persons without chronic kidney disease. Ann Intern Med 145:237-246 
8. Xiao J, Ding R, Xu X et al (2019) Comparison and development of machine learning tools in the prediction of chronic kidney disease progression. J Transl Med 17:119

9. Taron J, Weiß J, Martirosian P et al (2017) Clinical robustness of accelerated and optimized abdominal diffusion-weighted imaging. Invest Radiol 52:590-595

10. Moore WA, Khatri G, Madhuranthakam AJ, Sims RD, Pedrosa I (2014) Added value of diffusion-weighted acquisitions in MRI of the abdomen and pelvis. AJR Am J Roentgenol 202:995-1006

11. Kaga T, Noda Y, Mori T et al (2021) Diffusion-weighted imaging of the abdomen using echo planar imaging with compressed SENSE: feasibility, image quality, and ADC value evaluation. Eur J Radiol 142:109889

12. Rosenkrantz AB, Sigmund EE, Winnick A et al (2012) Assessment of hepatocellular carcinoma using apparent diffusion coefficient and diffusion kurtosis indices: preliminary experience in fresh liver explants. Magn Reson Imaging 30:1534-1540

13. Hori M, Fukunaga I, Masutani Y et al (2012) Visualizing non-Gaussian diffusion: clinical application of q-space imaging and diffusional kurtosis imaging of the brain and spine. Magn Reson Med Sci 11:221-233

14. Cheng J, Shao S, Chen W, Zheng N (2021) Application of diffusion kurtosis imaging and dynamic contrast-enhanced magnetic resonance imaging in differentiating benign and malignant head and neck lesions. J Magn Reson Imaging. https://doi.org/10.1002/jmri.27885

15. Zhang Q, Yu X, Ouyang H et al (2021) Whole-tumor texture model based on diffusion kurtosis imaging for assessing cervical cancer: a preliminary study. Eur Radiol 31:5576-5585

16. Yang L, Xia C, Zhao J, Zhou X, Wu B (2021) The value of intravoxel incoherent motion and diffusion kurtosis imaging in the assessment of tumor regression grade and $T$ stages after neoadjuvant chemoradiotherapy in patients with locally advanced rectal cancer. Eur J Radiol 136:109504

17. Sun K, Chen X, Chai W et al (2015) Breast cancer: diffusion kurtosis MR imaging-diagnostic accuracy and correlation with clinical-pathologic factors. Radiology 277:46-55

18. Liu Y, Zhang GM, Peng $X$ et al (2018) Diffusional kurtosis imaging in assessing renal function and pathology of IgA nephropathy: a preliminary clinical study. Clin Radiol 73:818-826

19. Zuo L, Ma YC, Zhou YH, Wang M, Xu GB, Wang HY (2005) Application of GFR-estimating equations in Chinese patients with chronic kidney disease. Am J Kidney Dis 45:463-472

20. Luciano RL, Moeckel GW (2019) Update on the native kidney biopsy: core curriculum 2019. Am J Kidney Dis 73:404-415

21. Katafuchi R, Kiyoshi Y, Oh Y et al (1998) Glomerular score as a prognosticator in IgA nephropathy: its usefulness and limitation. Clin Nephrol 49:1-8

22. Finsterbusch J (2012) Improving the performance of diffusion-weighted inner field-of-view echo-planar imaging based on 2D-selective radiofrequency excitations by tilting the excitation plane. J Magn Reson Imaging 35:984-992

23. Tamada T, Prabhu V, Li J, Babb JS, Taneja SS, Rosenkrantz AB (2017) Prostate cancer: diffusion-weighted MR imaging for detection and assessment of aggressiveness-comparison between conventional and kurtosis models. Radiology 284:100-108

24. Jensen JH, Helpern JA (2010) MRI quantification of non-Gaussian water diffusion by kurtosis analysis. NMR Biomed 23:698-710

25. Mao W, Ding Y, Ding X et al (2021) Pathological assessment of chronic kidney disease with DWI: Is there an added value for diffusion kurtosis imaging? J Magn Reson Imaging 54:508-517

26. Zhou H, Zhang J, Zhang XM et al (2021) Noninvasive evaluation of early diabetic nephropathy using diffusion kurtosis imaging: an experimental study. Eur Radiol 31:2281-2288

27. Jensen JH, Helpern JA, Ramani A, Lu H, Kaczynski K (2005) Diffusional kurtosis imaging: the quantification of non-Gaussian water diffusion by means of magnetic resonance imaging. Magn Reson Med 53:1432-1440

28. Wang WT, Yang L, Yang ZX et al (2018) Assessment of microvascular invasion of hepatocellular carcinoma with diffusion kurtosis imaging. Radiology 286:571-580

29. Mao W, Ding Y, Ding X, Fu C, Zeng M, Zhou J (2021) Diffusion kurtosis imaging for the assessment of renal fibrosis of chronic kidney disease: a preliminary study. Magn Reson Imaging 80:113-120

30. Fu J, Tang L, Li ZY et al (2020) Diffusion kurtosis imaging in the prediction of poor responses of locally advanced gastric cancer to neoadjuvant chemotherapy. Eur J Radiol 128:108974
31. Liu Z, Xu Y, Zhang J et al (2015) Chronic kidney disease: pathological and functional assessment with diffusion tensor imaging at 3T MR. Eur Radiol 25:652-660

32. Li Q, Wang D, Zhu X, Shen K, Xu F, Chen Y (2018) Combination of renal apparent diffusion coefficient and renal parenchymal volume for better assessment of split renal function in chronic kidney disease. Eur J Radiol 108:194-200

33. Zhao J, Wang ZJ, Liu M et al (2014) Assessment of renal fibrosis in chronic kidney disease using diffusion-weighted MRI. Clin Radiol 69:1117-1122

\section{Publisher's Note}

Springer Nature remains neutral with regard to jurisdictional claims in published maps and institutional affiliations.

\section{Submit your manuscript to a SpringerOpen ${ }^{\circ}$ journal and benefit from:}

- Convenient online submission

- Rigorous peer review

- Open access: articles freely available online

- High visibility within the field

- Retaining the copyright to your article

Submit your next manuscript at $\boldsymbol{\nabla}$ springeropen.com 